\title{
Business Model Flexibility and Software-intensive Companies: Opportunities and Challenges
}

\author{
Magnus Wilson*, Krzysztof Wnuk**, Lars Bengtsson*** \\ *Ericsson, Karlskrona, Sweden, Ericsson \\ ${ }^{* *}$ Department of Software Engineering, Blekinge Institute of Technology \\ *** Industrial Engineering and Management, LTH, Lund University \\ magnus.wilson@ericsson.com, krw@bth.se, lars.bengtsson@design.lth.se
}

\begin{abstract}
Background: Software plays an essential role in enabling digital transformation via digital services added to traditional products or fully digital business offerings. This calls for a better understanding of the relationships between the dynamic nature of business models and their realization using software engineering practices. Aim: In this paper, we synthesize the implications of digitalization on business model flexibility for software-intensive companies based on an extensive literature survey and a longitudinal case study at Ericsson AB. We analyze how software-intensive companies can better synchronize business model changes with software development processes and organizations. Method: We synthesize six propositions based on the literature review and extensive industrial experience with a large software-intensive company working in the telecommunication domain. Conclusions: Our work is designed to facilitate the cross-disciplinary analysis of business model dynamics and business model flexibility by linking value, transaction, and organizational learning to business model change. We believe that software engineering tools and methods can play a crucial role in enabling more automated synchronization between technology and business model changes.
\end{abstract}

Keywords: business flexibility, digital business modeling, equivocality, learning organization

\section{Introduction}

Digitalization brings new opportunities and increased connectivity is the primary fuel for digitalization. Ericsson, as a major player in the telecommunications market, is an actor deeply involved in this process ${ }^{1}$. The advent of the $5 \mathrm{G}$ network stands as a prominent example of opportunities and challenges associated with massive connectivity when all value-chain members and partners must rethink or reorganize their positions if necessary. For many companies, 5G will force them to redefine their business offerings and create new business opportunities. However, with this speed of technological changes, the business models can not remain static or re-actively respond to changes.
Digitalization drives significant changes to the process level, organization level, business level of any company and its customers [1]. Digitalization offers a significantly shorter transaction turnaround time. Consequently, the increased transaction speed drives new challenges for the alignment between business and technology changes. Companies that used to sell traditional products enter new markets and ecosystems where digital products and services dominate. The logic of creating these products, monetizing their core value, and maintaining them is significantly different and often counterintuitive at first glance. Thus, software engineers and managers often need to rethink their strategies and operational processes to better align with the nature of the digital business. An example here could be data-driven

\footnotetext{
${ }^{1}$ https://www.ericsson.com/en/reports-and-papers/networked-society-insights [last visited 23.06.2021].
} 
experimentation and feature discovery via A/B testing that significantly changes requirements engineering practice and demands great changes to software architecture [2].

This paper discusses the implications of digitalization for software-intensive companies based on an extensive literature survey and a longitudinal case study at Ericsson. We synthesize six propositions for improved handling of business model change and discuss each proposition's implications on software engineering practices and principles. This paper presents a cross-disciplinary synthesis of digitalization's impact on the alignment between business and technology change (including software engineering methods and tools). We also discuss new ways of handling business model flexibility in software-intensive product development.

Companies are undergoing significant transformations and are struggling with the alignment of business and technology changes [3]. Until recently, companies handled increasing size and complexity by 1) clearly distinguishing between the planning and realization layers for company strategy, product portfolios, and individual products; and 2) handling change mainly in the realization layer and ensuring that the planning layer remains reasonably stable.

Digitalization increases the speed of change in the planning layer, which in many cases, reaches the speed of changes in the realization layer. As a result, negotiation and risk management can no longer only rely on the sales and engineering departments, as the business models shift focus to the ecosystem and collaboration $[4,5]$, and companies choose operating multi-business-models [6]. Business modeling literature also recognizes the need for efficiently handling change as several authors discuss the dynamic nature of business models and change in the business environment, e.g., $[5,7,8]$, just to name a few.

The paper is structured as follows: In Section 2, we present our synthesis based on background and related work. In Section 3, we present how the business environment changes for our industry case and our findings from the longitudinal study. In Section 4, we summarize and discuss our results using the derived value membrane concept and develop one additional proposition. In Section 5, we conclude our paper.

\section{Background and related work}

The synthesis provided in this section is based on an extensive systematic literature review about efficiency, effectiveness [9], and flexibility of business modeling [10], published in our previous work and updated using the snowballing literature review method. It is also derived from our design science study on capturing changing business intents using context frames [11]. Our synthesis responds to multiple requests for cross-disciplinary research agenda [12-15]. The focal point of this study is the misalignment between the planning (define) and the realization (execute) of the software business in the fast-changing environment that a software-intensive company operates. A change to either the strategy or the realization has the potential to trigger an escalating misalignment. Formulating and executing a digitalization strategy [16] has the goal of reducing such misalignment by managing the change. The term digital transformation strategy implies a business-centric context when coordinating strategies for products, services, and business models as a whole.

Inspired by Ritter and Littl's focus on broader implications for business-model research, we take the analogy for the business model as a membrane between theories [12]. By analyzing uncertainty and equivocality [17] with value within a transaction, as the membrane between two actors in an activity system [13], we propose the business model can also act as the "contextual agent" in what we call the value membrane (VaM). This helps identify the cause of the misalignment and minimize gaps between needed change, planned change, and implemented change.

Most scholars focus on detecting or preparing change at one level (strategy, portfolio, or product) or analyzing the organization's broader external aspects, without integrating the activities [9]. Many scholars call for further research on change realization, e.g., [14, 18, 19]. Meier and Bosslau argue that there is almost no attention in 
research to the dynamic aspects, flexibility, validation, and implementation of business models [20], while Richter et al. emphasize the importance of understanding the degree of flexibility needed to realize change [21]. Seeing business models as activity systems helps organizations (as responsible for the business) adapt to change and generate value [15]. Therefore, our focus is primarily on the dynamics aspects of the business model change and business flexibility and its implications on software engineering.

\section{Research method}

We utilized the snowballing literature review method to collect relevant articles [22]. The start set was the articles identified in our two previous literature reviews $[9,10]$. These two studies used the following search string on the Google Scholar database:

SS1: (business modelling OR business model OR business ecosystem) AND value creation AND strategy,

SS2: ("business modelling" OR "business modeling" OR "business ecosystem") AND "business strategy" AND "value creation" AND ("effectiveness" OR "efficiency" OR "business flexibility" OR modularity OR "variability in realization" OR "governance" OR "multi-business").

Executing SS1 and SS2 (limited to title-abstract-keywords) and screening candidates left us with ten papers in the start set. After 4 snowballing iterations, we included 58 studies $[9,10]$. These 58 articles were screened to find new citations after 2018.

\subsection{Updates for new papers after 2018}

The previously selected 58 papers now became the start set for one snowballing iteration. As we are looking for new evidence, we only analyzed citations since references to these 58 papers were analyzed in our previous work $[9,10]$.

16833 new iterations were identified since 2018 and screened. From these citations, 60 ar- ticles were identified from the title and abstract screening. These 60 articles were carefully read and further evaluated. We excluded 40 papers because they were focusing on business model innovation by creating new business models. Six papers were excluded after the full read since they focused on a general notion of a business model. Fourteen papers were finally accepted and included in the synthesis. Next, we revisited the previously selected 58 papers from the previous literature review $[9,10]$. Each of these 58 papers was carefully screened and evaluated focusing on the implications of digitalization on business model change. We included seven papers from the 58 evaluated. The total set of papers used for the synthesis included 24 papers, detailed in Table 1 .

\subsection{Data analysis and synthesis}

The 24 papers included in the data analysis and synthesis were carefully investigated. We focused on analyzing patterns within the identified papers, according to the steps recommended by Cruzes [44]. Two authors read all 24 papers and identified relevant segments of text associated with digitalization and business model change. Next, these segments were discussed in a meeting, and 25 codes were identified using the open coding technique. Next, differences and similarities between these codes were discovered, and codes were merged into higher order statements. We focused on associating the 25 codes with the following categories: digitalization, value transformation, business model change, business flexibility, abstraction layers in business model change. Next, we constructed interpretations in each area and explored the relationships between the five themes (areas). Our high-order factors became the propositions presented in this paper. We provide the list of the most relevant articles from the set of 24 articles included in this work for each proposition. Our theory (frame of reference) was that digitalization has an impact on software engineering practices and product offering at Ericsson and also changes the current business models. 
Table 1. Selected papers including a short summary of the main contributions in these papers and the most associated propositions

\begin{tabular}{|c|c|c|c|}
\hline Paper & Authors & Comments & $\begin{array}{l}\text { Associated } \\
\text { Proposition(s) }\end{array}$ \\
\hline $\mathrm{P} 1$ & Woodard et al. [23] & $\begin{array}{l}\text { Digital business strategy and component architec- } \\
\text { tures }\end{array}$ & 3,6 \\
\hline P2 & Chew $[24]$ & Linking servitization and business model design & 4 \\
\hline P3 & Romero and Molina [5] & $\begin{array}{l}\text { Engineering dynamic business models with the help } \\
\text { of network organizations and customer communi- } \\
\text { ties }\end{array}$ & 1 \\
\hline $\mathrm{P} 4$ & Meier et al. [20] & $\begin{array}{l}\text { Dynamic business models for product-service sys- } \\
\text { tems }\end{array}$ & 3,4 \\
\hline P5 & Richter et al. [21] & $\begin{array}{l}\text { Flexibility in product-service systems via use-ori- } \\
\text { ented business models }\end{array}$ & 1,4 \\
\hline $\mathrm{P} 6$ & Eurich et al. [25] & $\begin{array}{l}\text { Business Model innovation process with network } \\
\text { thinking and holistic approach }\end{array}$ & 5 \\
\hline P7 & Mason and Mouzas [26] & Flexible business models and their architectures & 1,4 \\
\hline P8 & Gul $[27]$ & Changes in business models and digital strategy & 4,6 \\
\hline P9 & Sjödin et al. [28] & $\begin{array}{l}\text { Value creation and value capture in business model } \\
\text { innovation }\end{array}$ & 4 \\
\hline P10 & Antikainen [29] & Business Model Experimentation & 2,3 \\
\hline P11 & Trapp et al. [30] & Business model innovation tools & 5 \\
\hline $\mathrm{P} 12$ & Chritofi et al. [31] & $\begin{array}{l}\text { How agility and flexibility is discussed in business } \\
\text { research }\end{array}$ & 4 \\
\hline $\mathrm{P} 13$ & Teece [32] & Business Model and Dynamic Capabilities & 2 \\
\hline P14 & Linde et al. [33] & Value capture model for digital servitization & 2,5 \\
\hline P15 & Hacklin et al. [34] & Migrating value in business model innovation & 2,6 \\
\hline $\mathrm{P} 16$ & Vendrell-Herrero et al. [35] & $\begin{array}{l}\text { Business model experimentation in dynamic con- } \\
\text { texts }\end{array}$ & 3,4 \\
\hline P17 & Szopinski et al. [36] & Software tools for business model innovation & 5 \\
\hline P18 & Wirtz [37] & Drivers that trigger business model change & 2 \\
\hline P19 & Gebauer et al. [38] & Digitalization and servitization & 4 \\
\hline P20 & Moellers [39] & System dynamics in business model innovation & 3 \\
\hline P21 & Nailler et al. [40] & Business model evolution and value anticipation & 4 \\
\hline P22 & Clauss et al. [41] & Strategic agility and business model innovation & 2,5 \\
\hline P23 & Schaffer et al. [42] & Dynamic business models & $3,4,5$ \\
\hline P24 & Pratama and Iijima [43] & Linking value and business models & 2 \\
\hline
\end{tabular}

3.3. The longitudinal study, industrializing services at Ericsson

\subsubsection{Case study research design} and data collection methods

We report the case study objectives and other design aspects following guidelines suggested by Runeson and Höst [45] The objective of the case study was exploratory and focuses on digitalization and the resulting increased flexibility in offering of software-intensive products and services at Ericsson. Digitaliation is a contempo- rary complex phenomenon; therefore the best approach is to study it in a real world context. We opted for a holistic case study [46] with one unit of analysis (service organization). We decided to conduct a longitudinal case study at Ericsson, following the development and growth of the service organization and its impact on software engineering practices. Observations and participation took place for 4 years, giving us the opportunity to explore and understand the implications and impact of digitalization on business models and software engineering practices. 
Our goal was to explore the impact of service transformation on the business models that Ericsson offers and on software engineering practices utilized to execute these business models. Ericsson had a strong division between the research and development teams. The research organization mostly develops new solutions while the development organizations focus on deployment and customer adaptations for various global regions.

The theory associated with this case study assumes that the introduction of digital services impacts the ways of working and handling business operations. Since the offered products are mostly digital, their deployment could be continuous and remote, and their update time is drastically reduced. This has also impact on business models. Back in 2012, the Ericssons' service organization was mainly working in two types of business models:

- Managed Services - running the operator's network for them with large, long-term contracts.

- Service consultancy and Delivery model - focused on project deliveries and learning services.

As part of a corporate strategy, the service organization devised their strategic program "Global Scale - Local Reach", involving 75000+ resources (global, regional, and contractors) in nine regions, working in three segments of the service portfolio (Managed Services, Product Related Services, and Consulting and System Integration). The goal of the program was to improve customer responsiveness, improve productivity, and improve internal evaluation. The part of this transformation included either offering current products as services or creating services on top of the current software-intensive products. In many aspects, Ericsson followed the servitization transformation of the business environment[47].

Data Collection and Analysis Methods. We combined observations, document analysis, and interviews [48]. We also actively participated alongside program managers, the steering group, and requirements analysts. The research team has analyzed the collected empirical data and synthesized it in Section 5.2. Between 2012-2016, we actively worked alongside teams responsible for:

- supporting the program manager and his steering group with a business and enterprise architecture analysis,

- responsible for the business level requirements towards tools and IT development, and

- consultants for the deployment (business processes and training) into the sales and delivery organization (global plus nine regions).

At the beginning of the program (2012-2013), we participated in eleven extensive workshops interviewing practitioners from affected areas: finance; product management (services and software products); key account managers; Ericsson IT (master data, business processes, and system responsible); sales; delivery (project); and support processes (planning, development, and pricing, of services). The $3-4$ hours workshops were based on a short introduction to the workshop and the program, followed by practitioners presenting their current business processes and ways of working. Practitioners were then interviewed on current issues, and potential opportunities were discussed under the frame of the new program, providing us with great insights into the scope plus the strategical and operational issues facing the program. The workshops also provided a deeper understanding of uncertainty, equivocality, and rivalry between the different roles and organizations. We were also given continuous access to all program-related information, monthly reports, and steering group protocols. We also conducted two sets of individual, $60+$ minutes interviews with a delivery project manager and a solution architect, to identify any misalignment against the program's goals and the actual outcome.

\subsection{Validity threats}

We adopted the validity guidelines suggested by Runeson [45]. We mitigated the industrial experience bias of the leading author by involving the other two authors as reviewers of the work. We have also followed the thematic analysis approach steps [44]. The selected 24 papers are highly heterogeneous and therefore minimize the bias on 
specific author or terminology. To minimize the data synthesis bias, two researchers performed the initial read and coding, and these codes were later discussed and merged.

We minimized potential internal validity threats by following the snowballing literature review guidelines [22]. Because of the interdisciplinary nature of this study, the risk remains that some aspects are underrepresented and other aspects are over-represented. In particular, business model innovation or business process modeling seems to be heavily researched in the business management and the computer science community. However, we decided to focus on the interplay between business model change and digitalization and excluded papers that primarily focus on business model innovation realized by the creation of new business models.

Finally, we are aware that a single case study presented in this paper may not offer sufficient external validity. However, we opt for analytical generalization rather than statistical one as suggested by Flyvbjerg [49]. We provide an extensive description of the analyzed case and contrast it with the findings from the literature review.

\section{Results}

We have synthesized five propositions based on the literature review results and one based on the case study. We applied thematic synthesis to the papers presented in Table 1. The propositions are detailed in the subsections that follow.

\subsection{The impact of digital transformation on the nature of negotiating a business deal and equivocality}

Negotiating a business deal was traditionally a discussion focused on the functionality, price, and any potential project risks. The surrounding business environment (legislation, platforms and technology, partners and competition, etc.) gave little uncertainty related to the lifespan of the contract and the contractual obligations. Therefore, the negotiations could focus on the scope and usage of the underlying technical (soft- ware-based) solution. The business environment, including actors, business processes, and infrastructure, was predominately "stable within reasonable risks" throughout the lifespan of the contract and could be tracked by strategic planning, competitor and market analysis, monitoring standardization, and other regular management initiatives.

For example, the negotiations in the GSM and $3 \mathrm{G}$ telecommunication standardization included a well-defined business environment and interfaces between the components. Suppliers could concentrate their risk management to monitor and participate in the standards development while mainly focusing on optimal technology solutions for each component. Negotiating a new business deal was fundamentally about understanding what components, the quantity, and any potential customer-specific features needed to sweeten the deal. This kind of contractual flexibility could be implemented by the product and solution engineers under the strict coordination and risk management of sales, product management, and top management.

Software Engineering has developed several concepts to support contractual flexibility, e.g., implementing Software Product Lines (SPL), iterative, lean, and agile software development with daily code deliveries enabling increased customization. The ways of working need to be synchronized with other core business processes like sales and delivery, and hence into the business model. Product Service Systems (PSS) [50, 51], Industrial PSS [20, 52], and service-based business models $[53,54]$ are examples of how this fusion of engineering and business processes is continuously evolving.

With the digital transformation of the business environment [3, 55], negotiation and risk management can no longer rely on the sales and engineering departments but need to enact business model changes towards ecosystem and collaboration [4], [5]. Romero and Molina advocate collaborative networked organization and customer communities for supporting value co-creation and innovation [5]. These experience-centric networks help for co-creating value not only for the customers (like the previous sup- 
plier relationships) but also formulating alliances between the companies offering digital (software) products to its customers. The key enabler for these type of partnerships is openness in not only in shared source code but also Open Innovation initiatives [56]. This also means sharing software development tools and environments and openly discussing future plans and requirements.

Richter et al. suggest focusing on user-oriented business models that capture the necessary flexibility for product-service systems [21]. He includes agility as one of the aspects of changeability. Considering software development as a capital investment that should bring value to the customers is critical since software products need maintenance and operational support. This part is often neglected by Agile software development that focuses primarily on delivering new functionality rather than maintaining existing systems. Efficient maintenance improves long-term performance and changes the risk profile to asymmetric by introducing more flexibility early in the process.

Mason and Mouzas introduce the concept of "flexible business models" to capture and realize the necessary flexibility [26]. They include transaction relationships and ownership as the most critical aspects of flexibility. This has implications for software engineering since companies do not need to own the entire codebase and often co-create value in a software ecosystem. Gul describes what new strategies companies should realize in the digital environment, such as software [27].

The negotiating power, coming from knowing what business flexibility $(B F)$ can be offered and how this business flexibility is translated into contractual flexibility that can be absorbed by the business model realization. The realization should be done without jeopardizing the underlying effectiveness and efficiency of products and technical solutions (promised contractual characteristics); emerges as a critical competitive advantage. However, with more roles participating in the negotiation [11, Figure 7 p. 1182], uncertainty and equivocality (multiple and conflicting interpretations of a goal, situation, or task) can negatively impact the quality, cost, and lead-time of both the planning and realization phases $[17,57,58]$.

Companies undergoing the digitalization transformation should detect if the previously used realization strategy (the combination of the business model, products, and services) still will adhere to the changed contractual terms and conditions. This involves checking if the current business model will accommodate the new terms and conditions and the associated risks to deliver the changed contractual terms. The distance between strategizing, innovating, and planning for Business Model Change (BMCh) is significantly reduced. We argue that such risk management should be done before signing any contract, and therefore propose that,

Proposition 1: A mechanism for early detection of business model change is a critical factor in maintaining a company's negotiating power to ensure business success via improved risk management derived from the business flexibility.

The impact on software engineering. Software engineering should more clearly focus on risk management and negotiation. Risk management has traditionally been assigned to project management activities. Risk management in software engineering was performed assuming that the business model remains stable and the identified risks are most of technical nature [59]. We postulate that more effort should be dedicated to risk management on the requirements level. Some work was already done in the uniREPM model, where risk management is divided into project risk management and requirements risk management [60]. We believe that requirements risk analysis should be extended on the impact on business models and revenue strategies. Software managers should also consider software development as a capital investment that is long-term. This means taking care of software platforms and architectures and minimizing technical debt as much as delivering functionality and responding to ever-changing customer needs. Test automation is also a necessary component for keeping the negotiating power and understanding the limitations of the current codebase. 


\subsection{The gap between business model planning and execution}

Business model experimentation is gaining more importance for software companies as a response to a growing need for business model innovation [61] and digitalization [3]. Experimentation is an approach to achieve effective change to the business, driven by the rationale that in "highly uncertain environments, strategies are about insight, rapid experimentation, and evolutionary learning as much as the traditional skills of planning and rock-ribbed execution" [62]. Many companies that offer software products invest in product decision support based on experimentation and A/B testing [63]. Despite the unquestionable potential of online experimentation, they often provide very incremental improvements and are not suitable for radical strategic changes. Business model associated changes are often more radical than incremental. This contributes to a gap between business model planning and execution.

To analyze the gap between planning and execution, we complement Höfflinger's top-down definition of the business model with Rohrbeck et al. bottom-up definition of business modeling, "to be a creative and inventive activity that involves experimenting with content, structure, and governance of transactions that are designed to create and capture value" [64].

Rohrbeck et al. focus on experimenting as a "round-trip" process of "translating an idea into execution, test, evaluate, and change until satisfied" (similar to the agile method of developing software products followed up by proper retrospectives). Secondly, they also focus on transactions, connecting the business model to human behavior and value in execution and planning activities. Thirdly, they make a clear distinction between value created and captured, as two (role-dependent) views of a transaction, implying an information representation suitable for maintaining (observe, analyze, decide, change) many relationships to support effective and efficient collaborations (through all the stages of the business model lifecycle, e.g., plan, design, deployment, execution, phase out).
Antikainen et al. [29] suggest the business model experimentation method that supports companies in innovating their B2B business models by benefiting from the shared economy opportunities. The ownership principle is replaced by temporary access and reusing (the two embedded characteristics of software as one piece of software can be reused forever and shared with as many partners as required).

Linde et al. [33] suggest a framework for capturing value while designing, developing or scaling digital services. They highlight agile development and value co-creation (risk and reward sharing) as the two main elements of value and revenue creation for digital services. This moves the main responsibility for a service offering from primarily the software company to the ecosystem of partners that share the risks and benefits.

Teece [32] highlight the role of dynamic capabilities in responding to changing business needs and customer requirements. Software and software engineering capabilities should be considered as such dynamic capabilities that constitute the strength of business agility of digital organizations. As dynamic capabilities are underpinned in organizational routines, selecting the appropriate software development processes and caring about team values and culture becomes important for software organizations. Software companies often experience pivots or other radical changes. In these cases, organizations with high absorptive capability respond and often succeed in this transformation.

Hacklin et al. [34] describe how value is migrated during business model innovation in computer and telecommunication industries where value migrated to value-added service providers from device manufacturers, network providers, and infrastructure companies. This example shows clearly that software as the primary carrier of value not only can penetrate many industries but also disrupt value creation and capture in highly established and often regulated industries. This has deep implications for software engineering principles used by these companies.

Clauss et al. [41] describe how value creation and value capture relate to strategic agility in turbulent business environments. Wirtz [37] out- 
lines markets, technology, and deregulation as the main drivers for business model change. Software plays a key role in the deregulation of many industries, and the Open Source Movement removes monetary incentives in selling software as source code. Software products and services disrupt many "traditional" industries, such as for example finance or automotive. Therefore, software engineers have to remember that the potential of software innovation stretches greatly beyond the software industry.

Pratama and Iijma [43] describe how to translate the value proposition components from the existing business model to a new business model without losing the content. This approach has important implications for software engineering since the software is almost never fully disposed or destroyed, rather reused or reshaped with the new business idea in mind.

Inspired by Fjeldstad and Snow, we adopt the idea of value as the contingency variable affecting all other elements of the business model [15], and to understand the transaction- and role-dependent Direction of Value (DoV), we build on the value concept proposed in the Value Delivery Metamodel (VDML) [65]. Neither Höfflinger [8], Fjeldstad and Snow [15], nor VDML [65] makes a clear separation between value creation and value capture. Therefore, we postulate that:

Proposition 2: Value translation and value transformation capabilities are essential for business modeling. By exploring value, in an interaction on the individual level as the unit of analysis, we can resolve ambiguities in relation to the different areas of the business model (e.g., product delivery, product development, finance, customer relationships, partner management) stemming from: (1) the direction of value; (2) inter-level relationships of source and target for value; and (3) aggregation issues for value creation and value capture (scalability and value slippage).

Impact on Software Engineering. We postulate that business model experimentation should be integrated with data-driven continuous experimentation [66, 67]. For example, The RIGHT model for continuous experimentation is a good start as it has the business model and strategy element in the build-measure-learn process [66]. We believe that this integration should support the transformation into a "data-driven organization at scale" [67], where continuous experimentation is synchronized with business model evolution. We also postulate that software engineers need to consider two aspects when starting the development of new features or products: 1 ) what is the business viability of these features or products, and 2) how can we co-develop or co-create value.

\subsection{Handling business model change}

Both radical or incremental business model changes need to be addressed both at the planning and the realization levels [7]. Cavalcante et al. [68] divided BMCh into four types of change: business model creation, extension, revision, and termination. They further argued there is a "pre-stage" of "potential of BMCh" before the actual change occurs, often including analysis, experimentation, and other activities to build insights, learning, and commitment. In software engineering, this phase would include extensive prototyping or building the minimum viable product. Therefore, Cavalcante proposes to develop a detailed guide for analyzing $\mathrm{BMCh}$, both at the level of cognition as well as action, where he sees continuous experimentation and learning as fundamental pillars for effective BMCh, transforming the company into a "permanent learning laboratory".

To address change on the planning level, a company needs to understand the As-Is situation (which capabilities exist) and the effects on the To-Be situation (needed abilities). Such insights require understanding how strategy relates to a business model [23], tactics, and residual choices [69], in combination with what strategic agility [70] and level of strategic flexibility $[27,71]$ the organization has. This could be achieved by business model experimentation as pointed out by Antikainen [29] and highlighted in proposition 2. Flexible business models and their architecture appears to be the central concept here [26]. Dynamic business models and their depen- 
dencies in the complex software-intensive systems emerge as an area with increasing importance for further research [42].

To facilitate such insights, we propose to represent a business model by combining the work by Ghezzi's on value networks (VN) and resource management (RM) [72], with Osterwalder's business model canvas (BMC) [73]. Therefore, a company's need for business model change can be derived from having profound knowledge and a sound understanding of the three dimensions: (1) the customer(s) and related relationships; (2) the value proposition (revenue streams, what values to create, how to deliver it to the customer); and (3) the company's assets (products, resources, activities, cost structures, and partner relationships).

Woodard et al. [23] divide digital business strategy into design capital and design moves. The important but often invisible aspects of design capital are technical debt and option value. Both have a fundamental impact on the business agility of software development organizations. An organization holding significant technical debt loses a lot of flexibility in realization and has limited options for creating and delivering value.

Meyer and Boßlau [20] suggest developing both products and services at the same time and therefore capturing more customer value and building long-term relationships with the customers. This helps to integrate business model design and engineering activities. For software services, it appears to be very beneficial due to the possibility of dynamically deploying and updating software services for the customers.

Vendrell-Herrero [35] study the economic value of business model experimentation in many sectors and industries. Experimentation helps to strengthen the network effects and also capture value from various customer needs. Therefore, establishing software-driven experimentation is a way forward for many companies that are becoming software-intensive as it allows for exploring and understanding previously unknown externalities that could in the future become the core value proposition elements.

Moellers [39] utilized system dynamics during different phases of business model innovation.
Among the positive results is an improved understanding of how to accommodate a business model from a different context. This is important for software-intensive companies as they often operate in many domains and contexts and thus can reuse the business models between them.

Schaffer et al. [42] highlight understanding complex interactions of the sub-components within dynamic business models and their evolution and important emerging future topics.

To address change on the realization level, i.e., solutions implemented in products, processes, and organizations, literature discuss concepts like business model operationalization (BMO), implying reconfiguration, and tuning of the company's assets depending on the system dynamics [39], business model experimentation [61], [62], collaborative business modeling [5], business model experimentation [29, 35], Dynamic Software Product lines [74], R\&D as innovation experiment systems [75], just to name a few. With the advent of the digital business strategy [23], we propose that,

Proposition 3: Software companies possess a unique advantage for detecting and implementing business model change. Using their software development process to integrate their business model innovation with their product innovation, they can efficiently develop "native" product support for managing the linkage of contractual flexibility to the configuration of software products to achieve richer levels of business model experimentation and collaborative business modeling.

Impact on Software Engineering. We postulate that too much effort is dedicated to the creation and extension phases and too little effort on revision and termination. For example, requirements engineering focuses primarily on adding new features rather than reducing the complexity of the product (e.g., feature reduction [76]) or understanding stakeholder inertia and resistance to revolutionary change [77]. We believe that strategic planning of software platforms, e.g., SPL [78] should also include possible revisions or discontinuation of this platform, not forever extensions and growth. Moreover, software prod- 
ucts also end their life and get replaced by new products or new businesses [79]. We believe many business model changes should result in ending a product and replacing it with a new one rather than extensively changing or evolving it.

\subsection{Increasing business flexibility}

Flexibility helps organizations to "adapt when confronted with new circumstances...and provides the organization with the ability to respond quickly to market forces and uncertainty in the environment." [80]. Richter et al. point out that embedding flexibility into system design can optimize stakeholders' incentives, turning incomplete contracts into opportunities [21]. They discuss changeability as a term to better understand investments in flexibility related to value, cost, and risk. Changeability is defined by options under internal ("robustness" and "adaptability") respectively external control ("flexibility" and "agility").

In the business and management literature, flexibility is discussed in many different contexts, as related to business models and as ways to manage change, e.g., strategic flexibility [26, 71], resource and organizational flexibility versus dynamic capabilities [81], [82], [83], flexible business models and their architectures [26], dynamic business models in product-service systems [20, 21], linking servitization and business model design [24], and business model flexibility [26, 84].

Chritofi et al. provide a comprehensive literature summary of how agility and flexibility are described in the business literature [31]. They point out several organizational aspects that are relevant for software engineering research and practice, e.g. organizational process alignment, investments in intangible assets, and resource complementarity.

Gul [27] looks at how companies can gain a competitive advantage by executing digital strategies where production and storage are cheaper, deployment is faster, and organizations are collaborative and flexible. Software organizations need to become more collaborative (e.g., work in software ecosystems) and flexible in reusing OSS or previous software components to compete in this new business reality.
Sjödin et al. [28] advocate integrating value-creation and value-capture during value proposition definition, value provision design, and value-in-use delivery. They suggest a process for business model innovation that software-intensive companies can easily apply when designing and experimenting new products with the customers.

Nailler et al. [40] outline six processes by which business models evolve, motivated by the causal mechanism of value anticipation/realization. Gebauer et al. [38] discuss how to increase flexibility by introducing digital servitization.

We define Business Flexibility (BF), as the "negotiable options in: 1) Relationship; 2) Financial; and 3) the Value proposition between two parties trying to reach an agreement". These options enable effective negotiation to leverage a company's ability to compromise without breaking the promise in the final contractual agreement. The terms Relationship, Financial, and Value proposition refer to the context of Osterwalder's right side of the BMC [73]. Using the BMC, a company visualizes the strategic decisions and critical business options that characterize the rationale of the business idea and how it strategy-wise will be turned into a successful business (model) realization.

A change (on planning or realization level) is triggered by a gap (misalignment) in expectations and what is delivered. Closing these gaps (transforming a capability into an efficient ability) requires significant investments in time and effort, involving many collaborations. Closing this gap may also require changes in the digital strategy [27], extensive business model experimentation [35], the evolution of the current business model to anticipate more value [40], or a better understanding of the dynamics of current business models [42]. Therefore, we propose the following.

Proposition 4: Software companies have a unique opportunity for implementing business flexibility and efficiently creating value propositions. Software companies should develop software architectures and software functionality to enable a synchronized change in their business model. Impact on Software Engineering. We believe that the recent development in micro- 
-services [85] is a step towards greater flexibility in business model experimentation [29], and a better understanding of the system dynamics [39]. Many software companies offer services instead of products. This means they need to take a large part of the operational cost and also provide frequent updates and new releases. Understanding the product usage data helps to adapt the business models and the offering and therefore optimize the constant operational costs. This helps subscription-based software offerings to stay price competitive. Finally, data-driven experimentation for software products helps to combine value-creation and value-capture during product definition and evolution.

\subsection{Supporting dynamic business model change with the help of software tools}

Casadesus-Masanell and Ricart argued a clear distinction between strategy and the business model, where the business model "is a reflection of the firm's realized strategy" and that the strategy is the plan and process to reach the desired goal via the business model and onto tactics [69]. Strategy refers to the choice of the business model, while tactics refer to the possible realization choices.

Eurich et al. [25] suggest using network thinking as a tool for designing a business model. Dependencies and alternatives are discussed early in this process; this fits very well for software-intensive products as they can be composed of multiple components originating from various sources. Trapp et al. [30] develop a business model innovation identification tool that offers straightforward criteria and indicators to assist practitioners at accelerating BMI in established firms. They tested their tool in four large European corporations.

Bosch suggested a three-layer product model for managing growth and organizes product architecture into a commoditized functionality layer, a differentiating functionality layer, and an innovative and experimental functionality layer [86].
The creation of the business model design alternatives and the analysis of the interdependencies between the business models and the technological capabilities seems to be a promising way forward here [25].

Software tools can provide valuable support in this process by helping to automatically identify criteria and indicators to assist in accelerating business model change [30]. However, the problem remains as most software tools designed to support business modeling focus mainly on business model development rather than evolution [36]. However, most software systems are created once every 10-20 years and later updated, reused, and evolved [87]. This means that the support for this evolution is not covered by most business modeling tools, and the inherited powerful flexibility of software is not considered. Given this long-time perspective understanding strategic agility points [41] and supporting the dynamics aspect of the business models appears to be critical [42].

Proposition 5: Software development tools can provide valuable and mostly automated support for understanding the gap between the capabilities (what software does today) and the planned business model changes and adaptations.

Impact on Software Engineering. Software engineers can use many tools to support collaborative software development and automate many time-consuming tasks. We postulate that a large part of the data generated during the software development process can be used as input for understanding business flexibility and possible business opportunities from the developed software. An example here can be mutation testing that helps to understand the boundaries of software and its limitations beyond the specified or anticipated behavior [88]. Another example could be the data-driven extraction of features from the source code and understanding the offered quality aspects (e.g., security or performance). These aspects can provide valuable indicators for the directions of the business model change, not only for improving engineering activities. 


\section{Case study: adapting to the digital transformation in the telecommunication industry}

For Ericsson $\mathrm{AB}^{2}$, one critical aspect of achieving the business and technology transformation and managing change has been a long-term focus on industrialization and automation of the product development and the delivery (via process innovation). Digitalization requires additional strategies for handling the fast-paced business environment than driving technology standards. The technology innovation must be in concert with an equally dramatic and accelerating business model innovation. Ericsson's business model has evolved from the resource-centric, standard product-sales model, via several service models, over into different use models, where software-intensive products and services are now sold and delivered as-a-service and on-demand. Today, Ericsson is running multi-business-model operations, and with that, facing additional challenges to keep up with the pace of change. A majority of these challenges can be structured according to Ritter and Lettl's framework [12].

\subsection{Business model change at Ericsson}

Digitalization shifted the business risks to new dimensions, e.g., business ecosystem (sharing and collaborating in fierce competition), rather than optimizing its assets as a part of a value-delivery chain (e.g., traditionally mitigating risks with long-term business agreements and international standards). Such Business Model Change (BMCh), profoundly impacts the financial steering and control, as much of the investments need to be taken up-front, while the majority of revenues shift to on-demand usage rather than sales of products [20, 21]. The transition from business models based on selling products or hourly-rated services (with a strong focus on add-on sales), into value-based, knowledge-intensive, customer-unique use-models has affected many of Ericsson's dynamic and strategic capabilities and most of the core business processes.
For Ericsson, this also impacted the organizational design, requiring extended focus on organizational learning and incentives, governance, and management structures suited for the inherent dynamics, as well as collaborating with strategic and operational information. It also required enhanced clarity in responsibility and authority for the business model activities.

As a pilot, Ericsson applied the industrializing of the sales and delivery processes in $30+$ deliveries to customers in three regions during 2013. These pilot projects delivered contract scoping efficiency and accuracy improvement by $88 \%$ - The ordering process was considered simplified, while delivery lead time and project costs were reduced by $12-35 \%$. However, the program complexity and program duration were significantly underestimated (duration exceeded by $150 \%$ ). We identified three main reasons for the increased complexity:

- the scalability of the piloted solution turned out a bigger issue than anticipated.

- the inherent complexity (flexibility and re-usability) of the services to be industrialized and the services' dependency on the skills and knowledge of the service delivery staff.

- frequent re-organizations - this could be traced back to a substantial business model change together with insufficient support for fast and cross-organizational learning, negatively impacting the transformation program. The program struggled with two major challenges: 1) to decide what services to industrialize and which should remain "customer-specific", 2) to find the best balance for the new and updated IT tools to minimize disruptions to operations while concurrently updating the business processes.

The technical solution to the first challenge was basically divided into five parts, with a need for completely new tools to be integrated with existing tools and processes.

- Defining the granularity and scope of each service's content (covering all the different products and roles the services are related to).

${ }^{2}$ https://www.ericsson.com/en [last visited 26.06.2021]. 
- Defining the structure and content of the service catalog and the structure and representation of a service.

- The IT tools needed to plan, develop and deploy a service (so it's available in the product and service catalog ready for marketing, ordering, and sales).

- The IT tools needed in a delivery project to sell, order, plan, and deliver instances of services, plus the benchmark of projects and the outcome of each individual service and it's delivered instances.

- Non-industrialized services were managed manually with little or no automation.

The challenge of the dependency of the industrialized services from the skills and knowledge of the service delivery staff proved to be complex mainly due to the volume of implicit and explicit information in various forms of knowledge representations, and realizations with efficient knowledge management systems.

The decisions between investing in tool support versus investing in business process flexibility turned out to be very challenging for decision-makers and top management. As a consequence, the "traditional" IT update and integration process of new and existing tools to match the evolving business processes was affected by misunderstandings and delays leading to temporary solutions in the sales and delivery organization. Under customer pressure to deliver on signed contracts, this led to decreased trust between organizations, affecting the efficiency of the collaboration.

It also proved difficult to synchronize the business process development (sales and delivery processes to use industrialized services) with the agile Ericsson product development (the new generation of products to be delivered using the updated business processes). We identified the following four root causes of the misalignment:

- temporal effects due to different life cycles of these two core business processes,

- organizational steering, coordination, and incentives,

- expected capabilities that did not deliver on the requested abilities in customer projects, and
- the differences between the old and new product generations, the needed training of the service delivery staff, and their valuable customer experience feedback to the R\&D organization.

\subsubsection{Temporal effects of organizational learning}

The temporal effects of organizational learning created a gap between different organizations (R\&D, sales, delivery, and Ericsson IT) were occupied with their life-cycles of change as committed in earlier plans, see [11, Figure 5]. The symptoms of this were observed in areas of communication, coordination, training, and reporting, resulting in uncertainty, equivocality, and sub-optimization at best, and a lack of abilities at worst.

Scaling the solution was affected since planned capabilities needed by different organizations were not translated (in time) into required abilities, i.e., integrated tools and staff adequately trained in relation to the new or changed business processes (so they could perform the tasks demanded by the evolving business model). The scale of the industrialization problem was among the most significant factors since it affected the amount of information and the relationships between the affected organizations involved in the change processes. The rippling change-reaction escalated and started to violate existing goals, commitment, and reporting, leading to more efforts spent on temporary, local solutions to assure customer contracts could be honored.

\subsection{Case study results summary and synthesis}

Ericsson's traditional, engineering-centered industrialization approach would have benefited by categorizing the strategic program's requirements and associated risks into the five areas (strategic decisions, business logic, business model artifacts, misalignment, and $\mathrm{BMa}$ ) and highlighting that the program was actually facing a business model change. By addressing the misalignment between the effectiveness ("do the 
right thing" as a top-down strategic planning process) and the efficiency (as the bottom-up change of existing business models, business processes, organizations, and tools), we believe the scale of the program, as well as the temporal effects, could have been predicted and managed in a better way by proposing a set of different tactics, thereby invoking a higher degree of top management commitment and attention.

This study confirms opportunities and challenges for digitalization reported by scholars, for example, [6, 21, 24, 52]. Our interviews revealed that in practice, the scalability, the complexity of roles and (changing) business intents, and the size of the solution were perceived as the most significant challenges. Given the global, wide scope of the program and frequent organizational changes, establishing a reporting structure for how the different tactics supported each other (and executed by the different parts of the organization), turned out to be slow and inefficient, causing mistrust and unnecessary tensions. We believe this program would have benefited from a BMCh-centered approach, rather than a engineering-focused servitization approach, by achieving over-arching clarity and consensus between top-management, middle management, and the affected organizations, highlighting it was not just "business as usual".

The case study also highlights the added complexity of BMCh for large software companies that operate with contracts spawning years to complete. This calls for a combination of BMCh and organizational design. What appears to be inevitable is that the business environment will change during the execution of the underlying agreements. Our interview respondents believed that governance mechanisms should facilitate the exploration phase (Knowledge Creation process), transforming tacit knowledge into explicit knowledge fast enough and made it available through the Knowledge Management process.

We believe it requires fast, efficient feedback loops between $\mathrm{R} \& \mathrm{D}$, sales, and service delivery organizations, illustrating the continuous interaction between knowledge creation and knowledge management processes. Support for these loops should preferably be implemented both in the products as well as in the business processes. We, therefore, propose that,

Proposition 6: The practice of Digital Business Modeling (DBM) should be coined as a fusion between current practices of business modeling and requirement engineering, and become a key practice in facilitating business model innovation through experimentation.

\section{Conclusion}

Many distinguished scholars have highlighted the cross-disciplinary complexity stemming from the ongoing digitalization and transformation of the business environment $[3,13,14,89]$, just to name a few. This paper highlights three critical aspects of business modeling in the analysis of the misalignment between planning and execution. Firstly, focus on experimenting [64] as a "round-trip" process of "translating an idea into execution, test, evaluate, and change until satisfied" (similar to the agile method of developing software products). Secondly, focus on transactions, thereby connecting the business model to human behavior and value in execution and planning activities. Thirdly, the analysis is direction-sensitive, with minimum two (role-dependent) views of the transaction, implying an information representation suitable for maintaining (observe, analyze, decide, change) many relationships (through all the stages of the business model lifecycle) [11]. FInally, we analyze how software engineering methods and tools can support business model flexibility and promptly realizing business model changes.

This paper is an initial step for such a detailed, cross-disciplinary guide for handing business model change. Synthesizing from the two previous two literature reviews [9, 10], a design science study [11], and the case study presented in this paper, we present six propositions for addressing the challenges of aligning the planning and execution layers for software-intensive product development. We also highlight four critical aspects that software-intensive companies need to address: 
- Business model innovation for the business ecosystem, e.g., driven by markets and contextual changes, co-creation of value, collaboration within and between organizations, partners, communities, and customers, new streams of revenue while sharing of risks, revenues, and costs $[5,64]$.

- Software tools that focus on automation and integration of business and software architecture. These tools should support the shared economy aspect of new business models and the service-driven economy [90-92].

- Organizations prepared for experimentation and collaboration in a digital business world, affecting both the product development as well as the value delivery, e.g., agreement structures, incentives, processes, knowledge management and organizational learning, measurements of effectiveness and efficiency, revenues, cost, decision-making based on multifaceted optimization and transparency [93, 94].

- The level of integration and automation between the four processes of value creation, value capture, knowledge creation, and knowledge management $[95,96]$. This is the foundation for an innovative enterprise and should be nurtured as a key competitive advantage.

\section{Acknowledgment}

We would like to acknowledge that this work was supported by the KKS foundation through the S.E.R.T. Research Profile project at Blekinge Institute of Technology.

\section{References}

[1] P. Parviainen, M. Tihinen, J. Kääriäinen, and S. Teppola, "Tackling the digitalization challenge: how to benefit from digitalization in practice," International Journal of Information Systems and Project Management, Vol. 5, No. 1, 2017, pp. 63-77.

[2] S. Gupta, L. Ulanova, S. Bhardwaj, P. Dmitriev, P. Raff, and A. Fabijan, "The anatomy of a large-scale experimentation platform," in International
Conference on Software Architecture (ICSA). IEEE, 2018, pp. 1-109.

[3] C. Legner, T. Eymann, T. Hess, C. Matt, T. Böhmann, P. Drews, A. Mädche, N. Urbach, and F. Ahlemann, "Digitalization: Opportunity and challenge for the business and information systems engineering community," Business and Information Systems Engineering, Vol. 59, 2017, pp. 301-308.

[4] J. Moore, "The rise of a new corporate form," Washington Quarterly, Vol. 21, 1998, pp. 167-181.

[5] D. Romero and A. Molina, "Collaborative networked organisations and customer communities: value co-creation and co-innovation in the networking era," Production Planning and Control: The Management of Operations, Vol. 22, No. 5-6, 2011, pp. 447-472.

[6] Y. Snihur and J. Tarzijan, "Managing complexity in a multi-business-model organization," Long Range Planning, Vol. 51, No. 1, 2017, pp. 50-63.

[7] S.A. Cavalcante, "Preparing for business model change: the 'pre-stage' finding," Journal of Management and Governance, Vol. 18, 2014, pp. 449-469.

[8] N.F. Höflinger, "The business model concept and its antecedents and consequences - Towards a common understanding," Academy of Management Proceedings: Organization Development 83 Change, Vol. 2014:1, 2014.

[9] M. Wilson, K. Wnuk, J. Silvander, and T. Gorschek, "A literature review on the effectiveness and efficiency of business modeling," e-Informatica Software Engineering Journal, Vol. 12, No. 1, 2018, pp. 265-302. [Online]. http://www.e-informatyka.pl/attach/e-Inform atica_-_Volume_12/eInformatica2018Art11.pdf

[10] M. Wilson and K. Wnuk, "Business modeling and flexibility in software-intensive product development - a systematic literature review," in Challenges and Opportunities in the Digital Era. Springer International Publishing, 2018, pp. 292-304.

[11] J. Silvander, M. Wilson, K. Wnuk, and M. Svahnberg, "Supporting continuous changes to business intents," International Journal of Software Engineering and Knowledge Engineering, Vol. 27, 2017, pp. 1167-1198.

[12] T. Ritter and C. Lettl, "The wider implications of business-model research," Long Range Planning, 2017, pp. 1-8.

[13] C. Zott and R. Amit, "The business model: A theoretically anchored robust construct for strategic analysis," Strategic Organization, Vol. 11, No. 4, 2013, pp. 403-411. 
[14] D. Veit, E. Clemons, A. Benlian, P. Buxmann, T. Hess, D. Kundisch, J.M. Leimeister, P. Loos, and M. Spann, "Business models: An information systems research agenda," Business and Information Systems Engineering, Vol. 6, 2014, pp. $45-53$.

[15] O.D. Fjeldstad and C.C. Snow, "Business models and organization design," Long Range Planning, Vol. 51, No. 1, 2018, pp. 32-39.

[16] C. Matt, T. Hess, and A. Benlian, "Digital transformation strategies," Business and Information Systems Engineering, Vol. 57, 2015, pp. 339-343.

[17] P.E. Eriksson, P.C. Patel, D.R. Sjödin, J. Frishammar, and V. Parida, "Managing interorganizational innovation projects: Mitigating the negative effects of equivocality through knowledge search strategies," Long Range Planning, Vol. 49, No. 6, 2016, pp. 691-705.

[18] A. Osterwalder, Y. Pigneur, and C. Tucci, "Clarifying business models: Origins, present, and future of the concept," Communications of the Association for Information Systems, Vol. 15, No. 1, 2005, pp. 1-25.

[19] P. Ballon, "Business modelling revisited: the configuration of control and value," Info, Vol. 9, No. 5, 2007, pp. 6-19.

[20] H. Meier and M. Boßlau, "Design and engineering of dynamic business models for industrial product-service systems," in The Philosophers Stone for Sustainability. Springer, 2013, pp. 179-184.

[21] A. Richter, T. Sadek, and M. Steven, "Flexibility in industrial product-service systems and use-oriented business models," CIRP Journal of Manufacturing Science and Technology, Vol. 3, No. 2, 2010, pp. 128-134.

[22] C. Wohlin, "Guidelines for snowballing in systematic literature studies and a replication in software engineering," in Proceedings of the 18th International Conference on Evaluation and Assessment in Software Engineering, 2014, pp. $1-10$.

[23] C.J. Woodard, N. Ramasubbu, F.T. Tschang, and V. Sambamurthy, "Design capital and design moves: The logic of digital business strategy," MIS Quarterly: Management Information Systems, Vol. 37, No. 2, 2013, pp. 537-564.

[24] E.K. Chew, "Linking a service innovation-based framework to business model design," in 16th Conference on Business Informatics, Vol. 1. IEEE, 2014, pp. 191-198.

[25] M. Eurich, T. Weiblen, and P. Breitenmoser, "A six-step approach to business model innovation," International Journal of Entrepreneur- ship and Innovation Management, Vol. 18, No. 4, 2014, pp. 330-348.

[26] K. Mason and S. Mouzas, "Flexible business models," European Journal of Marketing, Vol. 46, No. 10, 2012, pp. 1340-1367.

[27] M. Gul, "Digital business strategies and competitive superiority," International Journal of Business Ecosystem, Vol. 2, No. 1, Feb. 2020, p. 17-31. [Online]. https://www.bussecon.com /ojs/index.php/ijbes/article/view/106

[28] D. Sjödin, V. Parida, M. Jovanovic, and I. Visnjic, "Value creation and value capture alignment in business model innovation: A process view on outcome-based business models," Journal of Product Innovation Management, Vol. 37, No. 2, 2020, pp. 158-183.

[29] M. Antikainen, A. Aminoff, and J. Heikkilä, "Business model experimentations in advancing b2b sharing economy research," in ISPIM Innovation Symposium. The International Society for Professional Innovation Management (ISPIM), 2018, pp. 1-12.

[30] M. Trapp, K.I. Voigt, and A. Brem, "Business models for corporate innovation management: Introduction of a business model innovation tool for established firms," International Journal of Innovation Management, Vol. 22, No. 01, 2018, pp. 18-40.

[31] M. Christofi, V. Pereira, D. Vrontis, S. Tarba, and A. Thrassou, "Agility and flexibility in international business research: A comprehensive review and future research directions," Journal of World Business, Vol. 56, No. 3, 2021, p. 101194. [Online]. https://www.sciencedirect.com/scienc e/article/pii/S1090951621000067

[32] D.J. Teece, "Business models and dynamic capabilities," Long Range Planning, Vol. 51, No. 1, 2018, pp. 40-49. [Online]. https://www.scienced irect.com/science/article/pii/S0024630117302 868

[33] L. Linde, J. Frishammar, and V. Parida, "Revenue models for digital servitization: A value capture framework for designing, developing, and scaling digital services," IEEE Transactions on Engineering Management, Vol. 5, No. 22, 2021, pp. $1-16$.

[34] F. Hacklin, J. Björkdahl, and M.W. Wallin, "Strategies for business model innovation: How firms reel in migrating value," Long Range Planning, Vol. 51, No. 1, 2018, pp. 82-110. [Online]. https://www.sciencedirect.com/science/article/ pii/S0024630117302881

[35] F. Vendrell-Herrero, G. Parry, M. Opazo-Basáez, and F.J. Sanchez-Montesinos, "Does business 
model experimentation in dynamic contexts enhance value capture?" International Journal of Business Environment, Vol. 10, No. 1, 2018, pp. $14-34$.

[36] D. Szopinski, T. Schoormann, T. John, R. Knackstedt, and D. Kundisch, "Software tools for business model innovation: Current state and future challenges," Electronic Markets, Vol. 30, No. 3, 2020, pp. 469-494.

[37] B.W. Wirtz, Adaptation and Modification of Business Models. Cham: Springer International Publishing, 2020, pp. 227-238.

[38] H. Gebauer, M. Paiola, N. Saccani, and M. Rapaccini, "Digital servitization: Crossing the perspectives of digitization and servitization," Industrial Marketing Management, Vol. 93, 2021, pp. 382-388. [Online]. https://www.sciencedirec t.com/science/article/pii/S0019850120304855

[39] T. Moellers, L. von der Burg, B. Bansemir, M. Pretzl, and O. Gassmann, "System dynamics for corporate business model innovation," Electronic Markets, Vol. 29, No. 3, 2019, pp. 387-406.

[40] C. Nailer and G. Buttriss, "Processes of business model evolution through the mechanism of anticipation and realisation of value," Industrial Marketing Management, Vol. 91, 2020, pp. 671-685. [Online]. https://www.sciencedirect.com/scienc e/article/pii/S0019850116302735

[41] T. Clauss, M. Abebe, C. Tangpong, and M. Hock, "Strategic agility, business model innovation, and firm performance: An empirical investigation," IEEE Transactions on Engineering Management, 2019, pp. 1-18.

[42] N. Schaffer, M. Pfaff, and H. Krcmar, "Dynamic business models: A comprehensive classification of literature," in Thirteenth Mediterranean Conference on Information Systems (MCIS 2019), 2019.

[43] N. Pratama and J. Iijima, "Value operation: Linking value in new business model creation process," in 23rd Pacific Asia Conference on Information Systems: Secure ICT Platform for the 4 th Industrial Revolution, PACIS, 2019, pp. 12-32.

[44] D.S. Cruzes and T. Dyba, "Recommended steps for thematic synthesis in software engineering," in 2011 International Symposium on Empirical Software Engineering and Measurement, 2011, pp. 275-284.

[45] P. Runeson and M. Höst, "Guidelines for conducting and reporting case study research in software engineering," Empirical Software Engineering, Vol. 14, 2009, pp. 131-164.

[46] R.K. Yin, Applications of case study research. Sage Publications, 2011.
[47] F. Adrodegari and N. Saccani, "A maturity model for the servitization of product-centric companies," Journal of Manufacturing Technology Management, 2020.

[48] T.C. Lethbridge, S.E. Sim, and J. Singer, "Studying software engineers: Data collection techniques for software field studies," Empirical software engineering, Vol. 10, No. 3, 2005, pp. 311-341.

[49] B. Flyvbjerg, "Five misunderstandings about case-study research," Qualitative inquiry, Vol. 12, No. 2, 2006, pp. 219-245.

[50] W. Reim, V. Parida, and D. Örtqvist, "Strategy, business models or tactics - What is product-service systems (PSS) literature talking about?" in Proceedings of the International Conference on Engineering Design, ICED, 2013, pp. 309-318.

[51] W. Reim, V. Parida, and D. Örtqvist, "Product-service systems (PSS) business models and tactics - a systematic literature review," Journal of Cleaner Production, 2014.

[52] H. Meier, R. Roy, and G. Seliger, "Industrial Product-Service systems - IPS2," CIRP Annals - Manufacturing Technology, Vol. 59, No. 2, 2010, pp. 607-627.

[53] D. Kindström, "Towards a service-based business model - Key aspects for future competitive advantage," European Management Journal, Vol. 28, No. 6, 2010, pp. 479-490.

[54] A. Zolnowski and T. Böhmann, "Business modeling for services: Current state and research perspectives," in AMCIS 2011 Proceedings, 2011, pp. $1-8$.

[55] A. Bharadwaj, O.A. El Sawey, P.A. Pavlou, N. Venkatraman, O.a. El Sawy, P.A. Pavlou, and N. Venkatraman, "Digital business strategy: Toward a next generation of insights," MIS Quarterly, Vol. 37, No. 2, 2013, pp. 471-482.

[56] H. Munir, K. Wnuk, and P. Runeson, "Open innovation in software engineering: a systematic mapping study," Empirical Software Engineering, Vol. 21, No. 2, 2016, pp. 684-723.

[57] X. Koufteros, M. Vonderembse, and J. Jayaram, "Internal and external integration for product development: The contingency effects of uncertainty, equivocality, and platform strategy," $D e$ cision sciences, Vol. 36, No. 1, 2005, pp. 97-133.

[58] A. Chang and C.C. Tien, "Quantifying uncertainty and equivocality in engineering projects," Construction Management and Economics, Vol. 24, 2006, pp. 171-184.

[59] B.W. Boehm, "Software risk management: principles and practices," IEEE Software, Vol. 8, No. 1, 1991, pp. 32-41. 
[60] M. Svahnberg, T. Gorschek, T.T.L. Nguyen, and M. Nguyen, "Uni-repm: validated and improved," Requirements Engineering, Vol. 18, No. 1, 2013, pp. 85-103.

[61] H. Chesbrough, "Business Model Innovation: Opportunities and Barriers," Long Range Planning, Vol. 43, No. 2-3, 2010, pp. 354-363.

[62] R.G. McGrath, "Business models: A discovery driven approach," Long Range Planning, Vol. 43, No. 2-3, apr 2010, pp. 247-261.

[63] R. Kohavi, D. Tang, and Y. Xu, Trustworthy online controlled experiments: A practical guide to a/b testing. Cambridge University Press, 2020.

[64] R. Rohrbeck, L. Konnertz, and S. Knab, "Collaborative business modelling for systemic and sustainability innovations," International Journal of Technology Management, Vol. 63, No. 1/2, 2013, p. 4.

[65] OMG, Value Delivery Modeling Language Specification, v1.0. Object Management Group, OMG.org, 2015, [Online; accessed 2018-08-08] http://www.omg.org/spec/VDML/AboutVDML/.

[66] F. Fagerholm, A. Sanchez Guinea, H. Mäenpää, and J. Münch, "The right model for continuous experimentation," Journal of Systems and Software, Vol. 123, 2017, pp. 292-305.

[67] A. Fabijan, P. Dmitriev, H.H. Olsson, and J. Bosch, "The evolution of continuous experimentation in software product development: From data to a data-driven organization at scale," in 39th International Conference on Software Engineering (ICSE), 2017, pp. 770-780.

[68] S. Cavalcante, P. Kesting, and J. Ulhøi, "Business model dynamics and innovation:(re)establishing the missing linkages," Management Decision, Vol. 49, 2011, pp. 1327-1342.

[69] R. Casadesus-Masanell and J.E. Ricart, "From Strategy to Business Models and onto Tactics," Long Range Planning, Vol. 43, No. 2-3, 2010, pp. 195-215.

[70] Y.L. Doz and M. Kosonen, "Embedding strategic agility: A leadership agenda for accelerating business model renewal," Long Range Planning, Vol. 43, No. 2-3, 2010, pp. 370-382.

[71] S. Schneider and P.A.T. Spieth, "Business model innovation and strategic flexibility: insights from an experimental research design," International Journal of Innovation Management, Vol. 18, No. 6, 2014, pp. 1-22.

[72] A. Ghezzi, "Revisiting business strategy under discontinuity," Management Decision, Vol. 51, No. 7, 2013, pp. 1326-1358.
[73] A. Osterwalder and Y. Pigneur, Business model generation: A handbook for visionaries, game changers, and challengers. Hoboken, NJ: Wiley, 2010.

[74] R. Capilla, J. Bosch, P. Trinidad, A. Ruiz-Cortés, and M. Hinchey, "An overview of dynamic software product line architectures and techniques: Observations from research and industry," Journal of Systems and Software, Vol. 91, 2014, pp. 3-23.

[75] H. Holmström Olsson, J. Bosch, and H. Alahyari, "Towards R\&D as innovation experiment systems: A framework for moving beyond agile software development," in Proceedings of the IASTED International Conference on Software Engineering, 2013, pp. 798-805.

[76] S. Marciuska, C. Gencel, X. Wang, and P. Abrahamsson, "Feature usage diagram for feature reduction," in International Conference on Agile Software Development. Springer, 2013, pp. 223-237.

[77] K. Wnuk, R.B. Svensson, and D. Callele, "The effect of stakeholder inertia on product line requirements," in Second IEEE International Workshop on Requirements Engineering for Systems, Services, and Systems-of-Systems (RESS). IEEE, 2012, pp. 34-37.

[78] K. Pohl, G. Böckle, and F.J. van Der Linden, Software product line engineering: foundations, principles and techniques. Springer Science \& Business Media, 2005.

[79] S. Jansen, K.M. Popp, and P. Buxmann, "The sun also sets: Ending the life of a software product," in Software Business, B. Regnell, I. van de Weerd, and O. De Troyer, Eds. Berlin, Heidelberg: Springer, 2011, pp. 154-167.

[80] H.C. Lucas and M. Olson, "The impact of information technology on organizational flexibility," Journal of Organizational Computing, Vol. 4, 1994, pp. 155-176.

[81] J. Barney, "Firm resources and sustained competitive advantage," Journal of management, Vol. 17, No. 1, 1991, pp. 99-120.

[82] R. Sanchez and J.T. Mahoney, "Modularity, flexibility, and knowledge management in product and organization design," Strategic Management Journal, Vol. 17, 1996, pp. 63-76.

[83] D.J. Teece, G. Pisano, and A. Shuen, "Dynamic capabilities and strategic management," Strategic Management Journal, Vol. 18, 1997, pp. 509-533.

[84] K.J.K. Mason and S. Leek, "Learning to Build a Supply Network: An Exploration of Dynamic 
Business Models," Journal of Management Studies, Vol. 45, No. 4, 2008, pp. 774-799.

[85] D. Namiot and M. Sneps-Sneppe, "On micro-services architecture," International Journal of Open Information Technologies, Vol. 2, No. 9, 2014, pp. 24-27.

[86] J. Bosch, "Achieving simplicity with the three-layer product model," Computer, Vol. 46, No. 11, Nov. 2013, pp. 34-39. [Online]. doi.ieee computersociety.org/10.1109/MC.2013.295

[87] J.C. Munson, "Software lives too long," IEEE Software, Vol. 15, No. 4, Jul. 1998, pp. 18, 20.

[88] Y. Jia and M. Harman, "An analysis and survey of the development of mutation testing," IEEE Transactions on Software Engineering, Vol. 37, No. 5, 2010, pp. 649-678.

[89] D. Romero and F. Vernadat, "Enterprise information systems state of the art: Past, present and future trends," Computers in Industry, Vol. 79, 2016, pp. 3-13.

[90] D. Olausson and C. Berggren, "Managing uncertain, complex product development in high-tech firms: In search of controlled flexibility," $R \& D$ Management, Vol. 15, 2010, p. 383-399.
[91] R. Capilla, J. Bosch, and K.C. Kang, Systems and Software Variability Management Concepts, Tools and Experiences. Berlin, Heidelberg: Springer, 2013.

[92] T. Magnusson and N. Lakemond, "Evolving schemes of interpretation: investigating the dual role of architectures in new product development," R\&D Management, Vol. 47, 2017, pp. $36-46$.

[93] F. Laloux and K. Wilber, Reinventing Organizations. Laloux, Frederic, 2014. [Online]. http: //www.reinventingorganizations.com/paywhat-feels-right.html

[94] D. Kahneman, Thinking, Fast and Slow. Farrar, Straus and Giroux, 2011.

[95] D.P. Lepak, K.G. Smith, and M.S. Taylor, "Introduction to special topic forum value creation and value capture: A multilevel perspective," Academy of Management Review, Vol. 32, 2007, pp. 180-194.

[96] C. Curado, "Organisational learning and organisational design," The Learning Organization, Vol. 13, No. 1, 2006, pp. 25-48. 